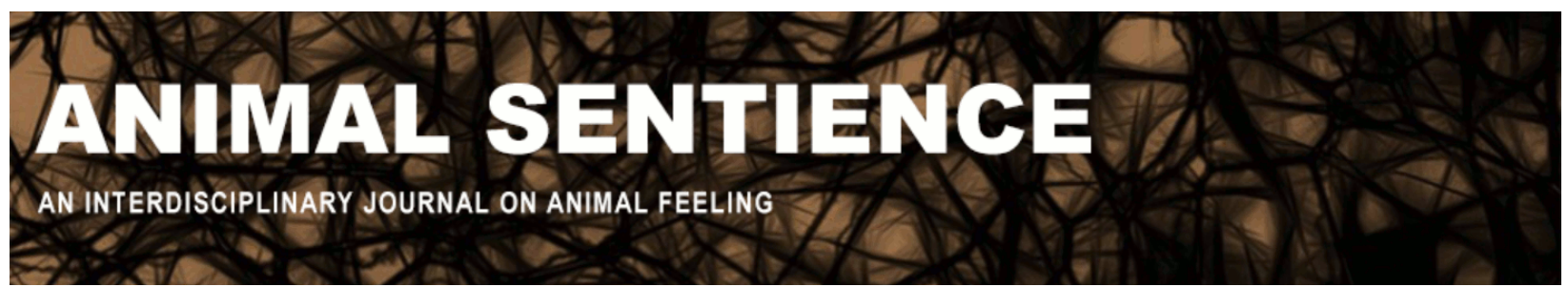

Brown, Culum, Prof. (2020) Convergent evolution of sentience?. Animal Sentience 29(25)

DOI: $10.51291 / 2377-7478.1617$

Date of submission: 2020-07-09

Date of acceptance: 2020-07-17

(c)

This article has appeared in the journal Animal

Sentience, a peer-reviewed journal on animal

cognition and feeling. It has been made open access,

free for all, by WellBeing International and deposited

in the WBI Studies Repository. For more information,

please contact

wbisr-info@wellbeingintl.org.

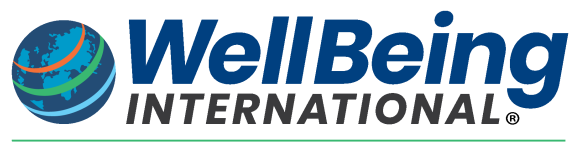

SOLUTIONS FOR PEOPLE, ANIMALS AND ENVIRONMENT 


\title{
Convergent evolution of sentience?
}

Commentary on Mikhalevich \& Powell on Invertebrate Minds

\section{Culum Brown}

Biological Sciences, Macquarie University

\begin{abstract}
Mikhalevich \& Powell make a compelling case that some invertebrates may be sentient and that our moral obligations in the context of welfare should hence extend to them. Although the case is similar to that made for fishes, there is one obvious difference in that examples of invertebrate sentience probably arose independently from vertebrate sentience. We have unequivocal proof that complex cognition arose multiple times over evolutionary history. Given that cognition is our best tool for indirectly quantifying sentience, it seems highly likely that this multiple polygenesis may also have occurred for sentience. In acknowledging this, we must accept that the anthropocentric structure-function arguments that have surfaced in the context of pain are almost certainly too simplistic and cannot account for cases of convergent evolution.
\end{abstract}

Culum Brown, Professor of vertebrate evolution at Macquarie University, is CoEditor of Fish Cognition and Behavior and Editor of the Journal of Fish Biology. He studies behavioural ecology of fishes with a special interest in cognition, personality and laterality. Website

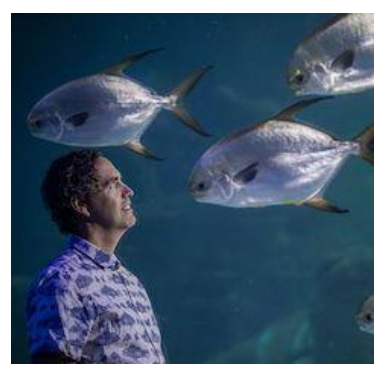

Mikhalavich \& Powell (2020) (M\&P) make a compelling case that our moral obligations in the context of welfare should extend to some invertebrates. On the whole, the argument is much the same as the one invoked over the past 20 years for including fishes in our moral circle (e.g., Sneddon et al 2018). The main difference, however, is one of phylogenic discontinuity.

As M\&P rightly point out, "invertebrates" are not a cohesive phylogenetic lineage. Many of the groups that exhibit complex cognition, and are probably sentient, are not recent vertebrate ancestors. Ironically, there is little evidence of complex cognition in the immediate ancestors of vertebrates - cephalochordata (lancelets) and Urochordata (tunicates). This strongly suggests that the cognitive sophistication observed in some invertebrate taxa arose completely independently. Indeed cephalopods, crustaceans and insects are themselves diverse taxa. Even within the Protostomes we must conclude that advanced cognition arose independently in multiple clades of arthropods (eg hymenoptera, crustacea) as well as within the molluscs (solely the cephalopoda).

This realisation has several implications for according welfare to invertebrates because the "other minds" in this instance are extremely different from our own. At least with fishes we can safely argue that the cognitive tool-box, the underlying brain structure and the nervous system are highly conserved across all vertebrates, which makes arguments of homology relatively simple. In the case of the protostomes, one needs to argue a case of independent, convergent evolution. There is little to no homology, although the clear and 
relevant examples include reward systems (and associated neuroanatomy and neurotansmitters; Perry \& Barron 2013) and nociceptors that are present in all Coelomates (Smith \& Lewin 2009).

This underscores that the simplistic, anthropocentric, structure-function view in the context of cognition and welfare has its limitations. Here the example I'm particularly thinking of is the misguided suggestion that mammalian pain is solely processed in the cortex (Key 2016). We are instead forced to accept that evolution often finds solutions to problems in a multitude of different ways. Pain perception has such obvious fitness benefits that it would be surprising if all animals did not have reasonably sophisticated ways of processing potentially harmful stimuli that go far beyond simple reflexes. We can state this as a clear fact about cognition given the well-known homologies and analogies among vertebrate brains (e.g., birds \& mammals) and between vertebrates and some invertebrate (insect and cephalopod) brains and their functional capacity. Given what we know about the evolution of cognition, it seems increasingly likely that sentience evolved more than once.

It seems unlikely that we will solve the other-minds problem any time soon. It is no longer just a philosophical conundrum, but a very real welfare issue for those animals that do have minds yet we mistakenly assume, or behave as if, they do not. Too many key questions remain unanswered: How many neurons and at what level of interconnectivity does it take for sentience to emerge? Are there degrees of sentience? What were the evolutionary drivers of sentience? In the meantime, we do have at our disposal a rich array of animal behaviour research findings that illustrate the cognitive capacity of certain invertebrates as M\&P have pointed out. At this point these are the best predictors of sentience at our disposal. And we are on very solid scientific ground because cognitive capacity can be measured quantitatively.

With appropriate experimental design we can adopt a comparative approach to indirectly quantifying sentience across all taxa (Walters 2018; Snedddon et al 2014; Dorey and Brown 2019). Key behavioural indicators in the context of pain research will include demonstrating that animals change behavioural preferences or choices when suffering from pain or that they trade off pain with other needs or requirements (food, shelter or friends). These behavioural tests show clearly that animals are responding to pain in a sophisticated manner and indicate cognitive engagement rather than simple reflexive or nociceptive responses.

It is an unfortunate reality that in order to study pain we must inflict it, albeit under very controlled conditions. We are on pretty solid moral grounds if we use this knowledge to show that animals do feel pain and that we can thereby eliminate cruelty wherever it may be found. We can also use cognition as a welfare indicator: For example, when investigating "valenced" affective states (emotions) we can use responses to ambiguous stimuli: subjects tend to display a positive view of the world when in good welfare but they become pessimistic when suffering from poor welfare (cognitive bias; Mendl et al 2010; Bateson et al 2011). Although the study of animal emotions is in its infancy, few in the animal behaviour world would deny that -- as suggested by Darwin -- affective states evolved as important drivers of behaviour. I suggest that this premise provides a relatively simple and unambiguous way forward for studying not only insects but all non-human animals (Dawkins 2000; Mellor 2011). 


\section{References}

Bateson, M., Desire, S., Gartside, S. E., \& Wright, G. A. (2011). Agitated honeybees exhibit pessimistic cognitive biases. Current Biology, 21(12), 1070-1073.

Perry, C.J. \& Barron, A.B. (2013) Neural mechanisms of reward in insects. Annual Review of Entomology, 58, 543-562.

Darwin, C (1872). Expression of Emotions in Man and Animals.

Dawkins, M. (2000) Animal minds and animal emotions. American Zoologist, 40, 883-888.

Dorey, C., \& Brown, C. (2019) Pain and emotion in fishes- Fish welfare implications for fisheries and aquaculture. Animal Studies Journal, 8, 175-201.

Key, B. (2016) Why fish do not feel pain. Animal Sentience 3(1)

Mendl, M., et al 2010 Dogs showing separation-related behaviour exhibit a pessimistic cognitive bias. Current Biology, 20, 839-840.

Mellor, D.J. 2011 Animal emotions, behaviour and the promotion of positive welfare states. New Zealand Veterinary Journal, 60, 1-8.

Mikhalevich, I. \& Powell, R. (2020) Minds without spines: Evolutionarily inclusive animal ethics. Animal Sentience 29(1)

Smith, E.S.J., \& Lewin, G.R. (2009). Nociceptors: A phylogenetic view. Journal of Comparative Physiology A, 195, 1089-1106.

Sneddon, L.U., Elwood, R.W., Adamo, S.A. \& Leach, M.C. (2014). Defining and Assessing Animal Pain. Animal Behaviour, 97, 201-12.

Sneddon, L.U., Woldenden, D.C.C. Leach, M.C., Valentim, A.M., Steenbergen, P.J., Nabila, B., Broom, D.M., Brown, C. (2018) Ample evidence for fish sentience and pain. Animal Sentience 21(17).

Walters, ET (2018) Defining pain and painful sentience in animals. Animal Sentience 21(14) 